\title{
Improved dietary diversity of school adolescent girls in the context of urban Northwest Ethiopia: 2017
}

\author{
Samuel Mersha Birru', Amare Tariku² and Aysheshim Kassahun Belew ${ }^{2 *}$
}

\begin{abstract}
Background: Undiversified diet increases the vulnerability of adolescents for different nutritional problems. Therefore, this study assessed dietary and associated factors among school adolescent girls in Gondar city, northwest Ethiopia.

Methods: A cross-sectional study was conducted from March to April 2017. Simple random sampling technique was used to select 778 adolescent school girls. A structured questionnaire was used to collect data. Multivariable logistic regression analysis was fitted to identify significant factors of dietary diversity. Adjusted Odds Ratio (AOR) with 95\% confidence interval was used to show the strength of association, while a $P$-value $<0.05$ of was used to declare the significance of association.

Results: This finding indicated that adolescent girls who met minimum dietary diversity with were $75.4 \%(95 \% \mathrm{Cl}(72.3,78.6)$. School type (AOR $=3.17,95 \% \mathrm{Cl}: 1.90,5.28)$ and residence (AOR $=2.0,95 \% \mathrm{Cl}: 0.84,3.01)$ were significantly associated with adequate dietary diversity.

Conclusions: Dietary practice of adolescent girls is good in Gondar City Administration. School type and residence of adolescents were significantly associated with minimum dietary diversity. Thus, Special attention needs to be paid on government school and rural adolescents to improve the intake of variety diet.
\end{abstract}

Keywords: School adolescent girls, Dietary diversity, Ethiopia

\section{Background}

Dietary diversity score (DDS) is defined as a number of individual food groups consumed over a given period of time [1]. It reflects quality diet at the household or individual level. In addition, DDS is measure of food security, nutrition information, early warning system and target of intervention at Global or national level [2, 3]. Mostly, monotonous staple diets lack essential micronutrients which lead to macro and micronutrient deficiencies, particularly in the most vulnerable group $[4,5]$.

Optimal nutrition is critical during adolescence as 50, 20 and $50 \%$ of adult weight, height, and skeletal mass are gained in this period [6-8]. However, $45-60 \%$ of adolescent girls are found with sub-optimal dietary intake [9] resulting in development of varied micronutrient deficiencies (Vitamin A, iron and iodine

\footnotetext{
* Correspondence: aysheshim121@gmail.com

${ }^{2}$ Department of Human Nutrition, Institute of Public Health, University of

Gondar, Gondar, Ethiopia

Full list of author information is available at the end of the article
}

deficiencies) [5, 8, 10-12]. Similar finding showed in Ethiopian 29 and $30 \%$ of adolescent girls had thinness and anemia, respectively [13]. Furthermore, delayed puberty, contracted pelvis and unfavorable birth outcomes are noted in undernourished adolescent girls [14, 15].

Globally, Only $17 \%$ of adolescents had diversified diet [16]. Similarly, $23.5-50 \%$ [17, 18] of the Iranian, $11.2 \%$ of Zimbabwe [19] and 26.8\% [4] Ethiopian Adolescents were reported as having adequate dietary diversity. Number of the researches documented that maternal education $[4,20]$, school type [20], occupation [20], nutritional knowledge [21], household food security [22], residence [4, 22] and wealth status $[4,20,22]$ were associated with dietary diversity of adolescents. Considering the burden of sub-optimal dietary intake, promotion of adequate dietary diversity becomes one of the global concerns [23]. However, the level of adolescent's dietary diversity is not well investigated in Ethiopia [4]. Therefore, this study assessed dietary diversity and associated factors among school adolescent girls in Gondar City Administration. 


\section{Methods}

A school-based quantitative cross-sectional study was conducted from March to April 2017 in Gondar City Administration; northwest Ethiopia. The City has 42 primary and 14 secondary and preparatory schools. All adolescent girls attending both private and governmental schools during the study period were considered as a source population.

A single population proportion formula was used to estimate sample size. Assumptions considered in sample size calculation were $26.8 \%$ as prevalence of adequate dietary diversity among adolescent high school girls in Gurage Zone [4], 95\% confidence level, 1.5 design effect, 10\% nonresponse rate and $4 \%$ degree of precision. Finally, a sample size of 778 was obtained. Schools were stratified into private and governmental schools and then ten schools were selected by lottery method. Simple random sampling technique was employed to choose samples using complete list of students as a sampling frame. Participants included in the study were proportional to the total students enrolled in private and governmental schools.

Concerning the data collection activity, interviewed based questionnaire was used to collect data. The tool was developed by reviewing different literatures, food and Agriculture Organization (FAO); FHI 360. Minimum Dietary Diversity for Women and health survey reports. Primarily the tool was prepared in English and translated to Amharic, the local language, and re-translated to English to check consistency of the questionnaire. Four data collectors (clinical nurses) and two BSc nurses as a supervisor were trained prior to data collection. The questionnaire was pretested among 39 school adolescent girls out of the study area. The training majorly encompasses dietary intake measurement and questionnaire administration techniques and ethical issues of the study.

The outcome, dietary diversity, was assessed using a standard tool suggested by Food and Agricultural Organization to measure women's dietary diversity. Food consumed by adolescents was assessed through 24-h recall method and then food items were categorized into ten food groups. Dietary Diversity Score (DDS) was created as a summary measure of dietary intake, accordingly participants who had DDS of five and above were deemed as having adequate dietary diversity, whereas inadequate DDS was ascertained when they had less than five DDS [24].

EPI INFO version 3.5.3 and SPSS version 20 were used for data entry and analysis, respectively. A binary logistic regression model was fitted to show the effect of exposure variables on dietary diversity. A variable screening criteria of $P$-value less than 0.2 was used in the bivariate analysis to select candidate variables for the final model, multi-variable logistic regression analysis. In the adjusted analysis, independent variables with a $P$-value of $<0.05$ were considered as independent factors associated with Dietary
Diversity. Model fitness was checked using HosmerLemeshow goodness of the fit test.

\section{Results}

A total of 768 adolescent girls participated in the study with a response rate $98.7 \%$. The mean age $( \pm$ SD) of the adolescent was $15.49( \pm 1.93)$ years. Majority $(79.3 \%)$ of respondents attended government schools. Substantial proportion (93.4\%) of samples lived in urban settlements and $74.3 \%$ of received less than three meals per day. About $33.7 \%$ of respondents were stunted, whereas, only $2.5 \%$ were thin for their height (Table 1 ). Home gardening was reported by $16 \%$ of the study participants. Almost all (98.4 and 98.5\%, respectively) households used water from improved sources and took less $30 \mathrm{~min}$ to fetch water in round trip (Table 2).

Table 1: Socio-demographic characteristics of school adolescent girls and their parents, Gondar City Administration, northwest Ethiopia, $2017(n=768)$

\begin{tabular}{|c|c|c|c|}
\hline Variables & & Frequency & Percent \\
\hline \multirow[t]{3}{*}{ Age } & Early & 130 & 16.9 \\
\hline & Middle & 402 & 52.3 \\
\hline & Late & 236 & 30.7 \\
\hline \multirow[t]{3}{*}{ Level of education } & Primary & 287 & 37.4 \\
\hline & High school & 417 & 54.3 \\
\hline & Preparatory school & 64 & 8.3 \\
\hline \multirow[t]{2}{*}{ Place of residence } & Urban & 717 & 93.4 \\
\hline & Rural & 51 & 6.6 \\
\hline \multirow[t]{5}{*}{ Occupation of mother } & Government employee & 124 & 16.1 \\
\hline & Housewife & 482 & 62.8 \\
\hline & Daily laborer & 39 & 5.1 \\
\hline & Merchant & 83 & 10.8 \\
\hline & Others & 40 & 5.2 \\
\hline \multirow[t]{2}{*}{ Media exposure } & Exposed & 608 & 79.2 \\
\hline & Not exposed & 160 & 20.8 \\
\hline \multirow[t]{2}{*}{ Food security } & Secured & 485 & 63.2 \\
\hline & In secured & 283 & 36.8 \\
\hline \multirow[t]{3}{*}{ Family wealth status } & Rich & 239 & 31.1 \\
\hline & Middle & 287 & 37.4 \\
\hline & Poor & 242 & 31.5 \\
\hline \multirow[t]{4}{*}{ Maternal education } & Unable to read and write & 427 & 55.6 \\
\hline & Primary & 117 & 15.2 \\
\hline & Secondary & 123 & 16 \\
\hline & College and above & 101 & 13.2 \\
\hline \multirow[t]{4}{*}{ Father's education } & Unable to read and write & 370 & 48.2 \\
\hline & Primary & 96 & 12.5 \\
\hline & Secondary & 125 & 16.3 \\
\hline & College and above & 177 & 23 \\
\hline
\end{tabular}


Table 2 Environmental characteristics of school adolescent girls in Gondar City Administration, Northwest Ethiopia, 2017

\begin{tabular}{llll}
\hline Variables & & Frequency & Percent \\
\hline Availability of home gardening & Yes & 123 & 16.0 \\
& No & 645 & 84.0 \\
Source of drinking water & Improved & 756 & 98.4 \\
& Unimproved & 12 & 1.6 \\
Wate water treatment & yes & 572 & 74.5 \\
Availability of home latrine & No & 196 & 25.5 \\
& yes & 607 & 79.0 \\
Hand washing after toilet & No & 161 & 21.0 \\
& No & 757 & 98.6 \\
\hline
\end{tabular}

Overall, 75.4\%(95\% CI: 72.3, 78.6) adolescent girls had adequate dietary diversity. Moreover, the mean dietary diversity score of participants was $5.76 \pm 1.81$. Majority ( 97 . $7 \%$ ) of adolescent girls consumed starchy staples (grains, roots and tuber). However, only $32.4 \%$ ate fruits (Fig. 1).

The logistic regression output illustrated that school type and maternal occupation were significantly associated with dietary diversity. Adolescents who attended private schools 3.2 (AOR =3:17; 95\% CI: 1.1.9, 5.28) and lived in urban areas (AOR $=2.0$; 95\% CI: 0.84, 3.01) had increased odds diversified diet (Table 3).

\section{Discussion}

This study illustrated that three-fourth (75.4\%) of adolescent girls had diversified diet. The finding was higher than the reports of developing countries, including Iran (26.55\%) [25], Zimbabwe (11.2\%) [26], Adama City (41. 2\%) [27], Gurage Zone (26.8\%) [4], Amhara region (21. $8 \%$ [28]. The high prevalence of adequate dietary diversity in this study area could be due to the nature of the study. Almost all (93.4\%) of adolescent girls were included from the urban kebeles and enrolled in schools. Such source of discrepancies could explain increased proportion of diversified diet. In addition, do not have information about better dietary intake habits [20]. However, the result was slightly lower than the study conducted in Agarfa, Ethiopia (80.4\%) [29]. This study used five food groups as cut-off point to determine adequate diversity, whereas the previous study considered four food groups. Use of low cut-off might inflate the prevalence of diversified diet in the former study. Obviously, dietary habit of developing nations is entirely depends on starchy staples [30]. This study also confirmed that almost all $(97.7 \%)$ of participants consumed grains, root and tubers. This result was supported with the previous local report [4].

The result of multivariate logistic regression analysis showed that adolescent girls from private schools had higher odds of diversified diet compared to those who attended governmental schools. In Ethiopia context, students enrolled in private schools are majorly from better-off families hence, poor families usually do not afford monthly school fee. High household socioeconomic status is key to enhance household and individual dietary diversity [25, 31, 32]. Adolescents living in better-off households could have improved nutrition information access because of better availability of media source [33].

Lastly, the odds of diversified diet were high in adolescent who lived in urban areas compared to those who lived in rural areas. This finding was supported by researches elsewhere [4, 23, 34, 35] conduct in, China children [36], Mali [34], Gurage [4] and Jimma Zone [22]. In fact, food security, socio-economic status and access to variety of food and information are higher in the urban settlements than the rural areas $[22,35,37,38]$. This might explain the observed difference in dietary diversity with place of residence. The study attempted to show

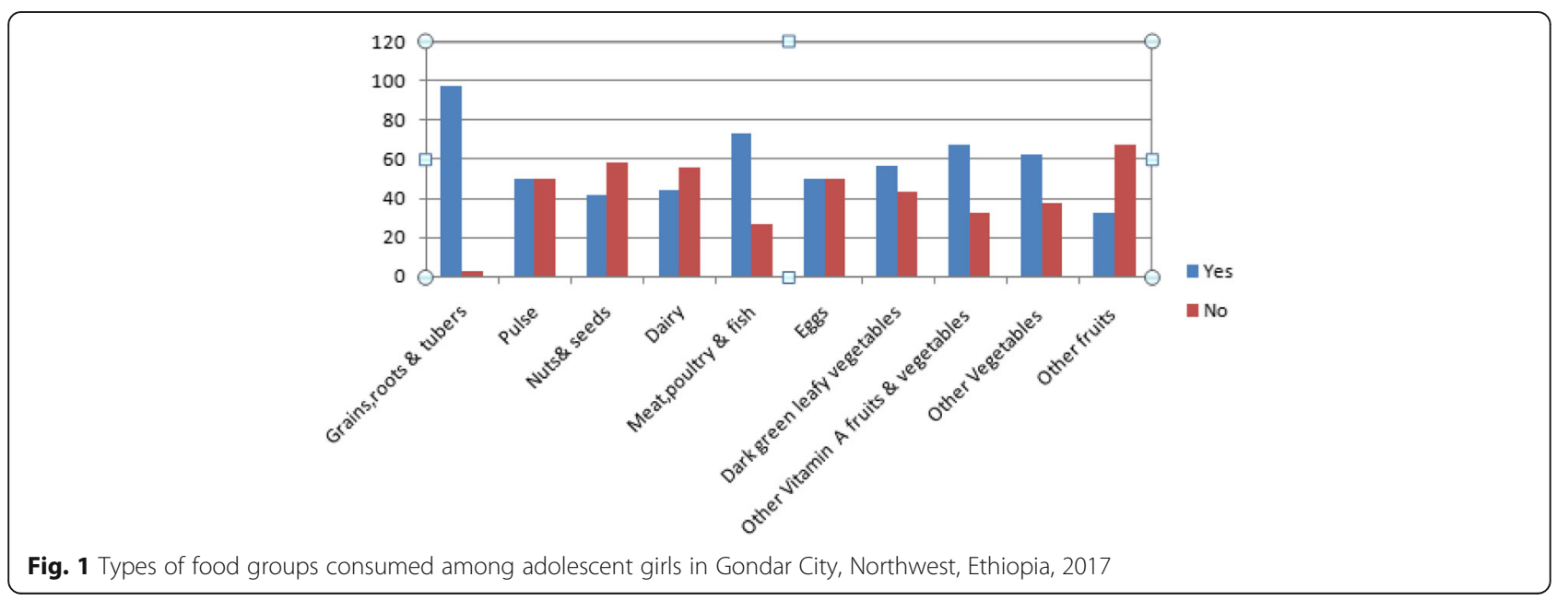


Table 3 Bivariate and multivariable logistic regression output showing that factors associated with dietary diversityamong school adolescent girls, Gondar City Administration, northwest Ethiopia, 2017

\begin{tabular}{|c|c|c|c|c|}
\hline \multirow[t]{2}{*}{ Variables } & \multicolumn{2}{|c|}{ Dietary diversity } & \multirow[t]{2}{*}{ Crude Odds Ratio with 95\% C) } & \multirow[t]{2}{*}{ Adjusted Odds Ratio with $95 \% \mathrm{Cl}$} \\
\hline & Adequate & Not adequate & & \\
\hline \multicolumn{5}{|l|}{ Age of adolescent } \\
\hline Early & $90(69.2 \%)$ & $40(30.8 \%)$ & 1 & 1 \\
\hline Middle & $216(53.7 \%)$ & $186(46.3 \%)$ & $0.52(0.34,0.79)$ & $1.25(0.71,2.20)$ \\
\hline Late & $93(39.4 \%)$ & $143(60.6 \%)$ & $0.29(0.18,0.46)$ & $1.01(0.51,2.01)$ \\
\hline \multicolumn{5}{|l|}{ School type } \\
\hline Government & $280(45.8 \%)$ & $332(54.2 \%)$ & 1 & 1 \\
\hline Private & $119(76.3 \%)$ & 37 (23.7\%) & $3.81(2.55,5.70)$ & $3.17(1.90,5.28)^{\mathrm{a}}$ \\
\hline \multicolumn{5}{|l|}{ Educational status of father } \\
\hline Informal education & $173(46.8 \%)$ & $197(53.2 \%)$ & 1 & 1 \\
\hline Primary & $44(49.9 \%)$ & $52(46.1 \%)$ & $0.96(0.61,1.51)$ & $0.81(0.50,1.31)$ \\
\hline Secondary & $77(61.6 \%)$ & 48 (38.4\%) & $1.83(1.20,2.76)$ & $1.27(0.77,2.09)$ \\
\hline College and above & $105(59.3 \%)$ & $72(40.7 \%)$ & $1.66(1.12,2.39)$ & $0.98(0.60,1.64)$ \\
\hline \multicolumn{5}{|l|}{ Educational status of mothers } \\
\hline Informal education & $193(45.2 \%)$ & $234(54.8 \%)$ & 1 & 1 \\
\hline Primary & $69(59 \%)$ & $48(41 \%)$ & $1.74(1.15,2.64)$ & $1.24(0.78,1.96)$ \\
\hline Secondary & $72(58.5 \%)$ & $51(41.5 \%)$ & $1.71(1.14,2.57)$ & $1.05(0.62,1.79)$ \\
\hline College and above & $65(64.4 \%)$ & $36(35.6 \%)$ & $2.19(1.40,3.43)$ & $1.38(0.69,2.76)$ \\
\hline \multicolumn{5}{|l|}{ Occupation of the mothers } \\
\hline Government employee & 69 (55.6\%) & 55 (44.4\%) & $1.39(0.68,2.83)$ & $1.61(0.74,3.53)$ \\
\hline Housewife & $241(50 \%)$ & $241(50 \%)$ & $1.10(0.58,2.11)$ & $1.65(0.81,3.33)$ \\
\hline Daily laborer & $17(43.6 \%)$ & $22(56.4 \%)$ & $0.85(0.35,2.07)$ & $1.26(0.49,3.29)$ \\
\hline Merchant & $53(63.9 \%)$ & $30(36.1 \%)$ & $1.95(0.91,4.20)$ & $2.42(1.06,5.53)$ \\
\hline Others & $19(47.5 \%)$ & $21(52.5 \%)$ & 1 & 1 \\
\hline \multicolumn{5}{|l|}{ Wealth status } \\
\hline 1st quintile & 75 (45.5\%) & $90(54.5 \%)$ & $0.52(0.34,0.79)$ & $0.78(0.47,1.29)$ \\
\hline 2nd quintile & $100(47.2 \%)$ & $112(52.8 \%)$ & $0.55(0.37,0.82)$ & $0.80(0.51,1.25)$ \\
\hline 3rd quintile & $106(53 \%)$ & $94(47 \%)$ & $0.70(0.47,1.04)$ & $0.85(0.54,1.31)$ \\
\hline 4th quintile & $118(61.8 \%)$ & $73(38.2 \%)$ & 1 & 1 \\
\hline \multicolumn{5}{|l|}{ Availability of latrine } \\
\hline Yes & $324(53.4 \%)$ & $283(46.6 \%)$ & $1.31(0.93,1.86)$ & $0.88(0.60,1.32)$ \\
\hline No & $75(46.6 \%)$ & $86(53.4 \%)$ & 1 & 1 \\
\hline \multicolumn{5}{|l|}{ Stunting } \\
\hline Stunted & $115(44.4 \%)$ & $144(55.6 \%)$ & 1 & 1 \\
\hline Normal & $284(55.8 \%)$ & $225(44.2 \%)$ & $1.58(1.17,2.14)$ & $1.00(0.70,1.42$ \\
\hline \multicolumn{5}{|l|}{ Residence } \\
\hline Urban & $380(53 \%)$ & $337(47 \%)$ & $1.90(1.06,3.41)$ & $2.00(0.84,3.01)^{\mathrm{a}}$ \\
\hline Rural & 19 (37.3\%) & $32(62.7 \%)$ & 1 & 1 \\
\hline \multicolumn{5}{|c|}{ Respondents educational status } \\
\hline $5-8$ & $184(64.1 \%)$ & $103(35.9 \%)$ & 1 & 1 \\
\hline $9-10$ & $197(47.2 \%)$ & $220(52.8 \%)$ & $0.50(0.37,0.68)$ & $0.69(0.46,1.03)$ \\
\hline $11-12$ & $18(28.5 \%)$ & 46 (71.9\%) & $0.22(0.12,0.40)$ & $0.23(0.11,0.50)$ \\
\hline
\end{tabular}

indicate significant at $p$ value less than 0.05 in multivariable logistic analysis 
dietary diversity in the most vulnerable group of the population representing the rural northwest Ethiopia, but, some of the limitations of this study should be taken into consideration. First, the study did not consider the quantity of food consumed by the adolescent and single $24 \mathrm{~h}$ recall did not indicate the usual dietary habit of the adolescent. There might be social desirability bias in responding type food given to children and recall bias.

\section{Conclusions}

In summary, the prevalence of adequate dietary diversity is high in Gondar City Administration. Type of school and place of residence were significantly associated with adolescent's dietary diversity. Hence, efforts focusing to improve dietary diversity should give special attention to government schools and the rural adolescents.

\section{Abbreviations}

AOR: Adjusted Odds Ratio; BSC: Bachelors of Science; Cl: Confidence Interval; COR: Crud Odds Ratio; DDS: Dietary Diversity Score; FAO: Food and Agriculture Organization; SPSS: Statistical Package for Social Sciences

\section{Acknowledgements}

The authors would like to thank all respondents for their willingness to participate in the study. They are also grateful to all school principals, teachers, and parents for their cooperation and University of Gondar for material support.

\section{Funding}

No fund was obtained for this study.

\section{Availability of data and materials}

Data will be available upon request from the corresponding authors.

\section{Authors' contributions}

SM conceived the study, developed the tool, coordinated the data collection activity, and carried out the statistical analysis. AK participated in the design of the study, tool development, and drafting the manuscript. AT participated in the design of the study and tool development, performed statistical analysis, and reviewed the manuscript. All authors read and approved the final manuscript.

\section{Ethics approval and consent to participate}

Ethical clearance was obtained from the Institutional Review Board of the University of Gondar. Official letters of co-operation submitted to all primary, secondary schools and city administration education office. Students and their parents were notified and necessary explanations were also given about the purposes, procedure and ethical issues of the study. Consent was collected from the parents of study subjects by sending letter to parent/guardians for each study subject less than 18 years old and oral assent was also obtained from study subjects in the school. The purpose of the study was explained and written informed consent was secured. Confidentiality was maintained at all levels of the study. Participant's involvement in the study was on voluntary basis; participants who were not volunteer to participate in the study and those who wish to quit their participation at any stage were informed to do so without any restriction. The respondents' confidentiality of information was assured by excluding names and identifiers from in the questionnaire.

\section{Competing interests}

The authors declare that they have no competing interest.

\section{Publisher's Note}

Springer Nature remains neutral with regard to jurisdictional claims in published maps and institutional affiliations.

\section{Author details}

Gondar University Teaching and Referral Hospital, University of Gondar, Gondar, Ethiopia. ${ }^{2}$ Department of Human Nutrition, Institute of Public Health, University of Gondar, Gondar, Ethiopia.

Received: 20 February 2018 Accepted: 16 April 2018

Published online: 25 April 2018

\section{References}

1. FHI F. 360. Minimum dietary diversity for women: a guide for measurement Rome. Italy: FAO; 2016

2. Kennedy G, Ballard T, Dop MC. Guidelines for measuring household and individual dietary diversity: food and agriculture Organization of the United Nations; 2011

3. Korkalo L, Erkkola M, Heinonen AE, Freese R, Selvester K, Mutanen M. Associations of dietary diversity scores and micronutrient status in adolescent Mozambican girls. Eur J Nutr. 2017;56(3):1179-89.

4. Worku M, Hailemicael G, Wondmu A. Dietary diversity score and associated factors among high school adolescent girls in Gurage zone, Southwest Ethiopia. World journal of. Nutr Health. 2017:5(2):41-5.

5. Delisle HIn, Organization WH. Nutrition in adolescence: issues and challenges for the health sector: issues in adolescent health and Development 2005.

6. Shahid A, Siddiqui FR, Bhatti MA, Ahmed M, Khan MW. Assessment of nutritional status of adolescent college girls at Rawalpindi. Annals of King Edward Medical University. 2010;15(1):11.

7. Nutrition C. Nutrition in adolescence-issues and challenges for the health sector. 2005.

8. Organization WH. Adolescent nutrition: a review of the situation in selected south-east Asian countries. 2006

9. Shashikantha S, Sheethal M, Vishma B. Dietary diversity among women in the reproductive age group in a rural field practice area of a medical college in Mandya district, Karnataka, India. International journal of community medicine and. Public Health. 2017;3(3):746-9.

10. Best C, Neufingerl N, Van Geel L, van den Briel T, Osendarp S. The nutritional status of school-aged children: why should we care? Food Nutr Bull. 2010:31(3):400-17.

11. Ahmed F, Zareen M, Khan MR, Banu CP, Haq MN, Jackson AA. Dietary pattern, nutrient intake and growth of adolescent school girls in urban Bangladesh. Public Health Nutr. 1998;1 (2):83-92.

12. Manson J, Lotfi M, Dalmiya N, Sethuraman K, Deitchler M, Geibel S, et al. The micronutrient report: current progress in the control of vitamin a, iodine, and iron deficiencies. Micronutrient initiative. Ottawa: International Development Research Center; 2001.

13. Ethiopia Demographic and Health survey. Ethiopia demographic and health survey report. Central statistical Agency,Addis Ababa, Ethiopia,ICF International,Calverton, Maryland. In: USA; 2016.

14. Begum A, Sharmin K, Hossain M, Yeasmin N, Ahmed T. Nutritional status of adolescent girls in a rural area of Bangladesh: a cross sectional study. Bangladesh Journal of Scientific and Industrial Research. 2017:52(3):221-8.

15. Hossen K, Rahman F, Mashreky SR. Nutritional status of adolescent girls in Bangladesh: findings of a community based survey. South East Asia. Journal of Public Health. 2016;6(1):3-7.

16. JSI Research \& Training Institute I. Review of programmatic responses to adolescent and Women's nutritional needs in low and middle income countries. 2015.

17. Ghasemifard N, Akhlaghi M, Faghih S. Diet quality of adolescents in shiraz, southern Iran needs moderate to severe improvement. International journal of nutrition. Sciences. 2017;2(2):66-72

18. Mirmiran P, Azadbakht L, Esmaillzadeh A, Azizi F. Dietary diversity score in adolescents-a good indicator of the nutritional adequacy of diets: Tehran lipid and glucose study. Asia Pac J Clin Nutr. 2004;13(1):56-60.

19. Minister of Health and Child Care. Zimbabwe National Nutrtion strategy. 2014-2018.

20. Belachew T, Hadley C, Lindstrom D. Differentials in measures of dietary quality among adolescents in Jimma zone, Southwest Ethiopia. Ethiop Med 1. 2008:46(2):133-42

21. Oldewage-Theron W, Egal A, Moroka T. Nutrition knowledge and dietary intake of adolescents in Cofimvaba, eastern cape, South Africa. Ecology of food and nutrition. 2015;54(2):138-56. 
22. Belachew T, Lindstrom D, Gebremariam A, Hogan D, Lachat C, Huybregts L, et al. Food insecurity, food based coping strategies and suboptimal dietary practices of adolescents in Jimma zone Southwest Ethiopia. PLoS One. 2013:8(3):e57643.

23. Organization WH. Global strategy on diet, physical activity and health: a framework to monitor and evaluate implementation. 2006.

24. Kennedy G, Razes M, Ballard T, Dop M, editors. Measurement of dietary diversity for monitoring the impact of food based approaches. International symposium on food and nutrition security, Rome; 2010.

25. Vakili M, Abedi P, Sharifi M, Hosseini M. Dietary diversity and its related factors among adolescents: a survey in Ahvaz-Iran. Global journal of health science. 2013;5(2):181.

26. Reese MA. Assessment of adolescent girl nutrition, dietary practices, and roles in Zimbabwe. International Medical Corps: Zimbabwe; 2015.

27. Roba K, Abdo M, Wakayo T. Nutritional status and its associated factors among school adolescent girls in Adama City. Central Ethiopia J Nutr Food Sci. 2016;6(493):2.

28. Wassie MM, Gete AA, Yesuf ME, Alene GD, Belay A, Moges T. Predictors of nutritional status of Ethiopian adolescent girls: a community based cross sectional study. BMC Nutrition. 2015;1(1):20.

29. Mohammed AY, Nutritional Status TTB. Associated risk factors among adolescents girls in Agarfa high school, south East Ethiopia. International journal of nutrition and food. Sciences. 2015;4(4):445-52.

30. Ochola S, Masibo PK. Dietary intake of schoolchildren and adolescents in developing countries. Annals of. Nutrition and Metabolism. 2014; 64(Suppl. 2):24-40.

31. Gebreyohannes Y, Shiferaw S, Demtsu B, Bugssa G. Nutritional status of adolescents in selected government and private secondary schools of Addis Ababa, Ethiopia. Adolescence. 2014;10:11.

32. Kiboi W, Kimiywe J, Chege P. Determinants of dietary diversity among pregnant women in Laikipia County, Kenya: a cross-sectional study. BMC Nutrition. 2017;3(1):12.

33. Corbett D. Brown. Adolescent and adult perceptions of adolescent diet, physical activity, body size, and obesity prevention in Botswana: University of Pennsylvania; 2014

34. Torheim L, Ouattara F, Diarra M, Thiam F. Nutrient adequacy and dietary diversity in rural Mali: association and determinants. Eur J Clin Nutr. 2004;58(4):594.

35. Mehlawat U. Dietary diversity score of college going students (17-21 years) and its association with family income in India. The Indian Journal of Nutrition and Dietetics. 2015;52(3):277-85.

36. Zhao W, Yu K, Tan S, Zheng Y, Zhao A, Wang P, et al. Dietary diversity scores: an indicator of micronutrient inadequacy instead of obesity for Chinese children. BMC Public Health. 2017;17(1):440.

37. Gautam R, Suwal R, Sthapit B, editors. Assessment of dietary diversity: A basis for promoting plant genetic species in home gardens. Home Gardens in Nepal: Proceeding of a workshop on "Enhancing the contribution of home garden to on-farm management of plant genetic resources and to improve the livelihoods of Nepalese farmers: Lessons learned and policy implications", 6-7 August 2004. Pokhara: LI-BIRD, Bioversity International and SDC Local Initiatives for Biodiversity; 2006.

38. Silangwe BN. Nutritional status and dietary intake of adolescent girls in Mandlenkosi high school, Lindelani 2013.

\section{Ready to submit your research? Choose BMC and benefit from:}

- fast, convenient online submission

- thorough peer review by experienced researchers in your field

- rapid publication on acceptance

- support for research data, including large and complex data types

- gold Open Access which fosters wider collaboration and increased citations

- maximum visibility for your research: over $100 \mathrm{M}$ website views per year

At BMC, research is always in progress.

Learn more biomedcentral.com/submissions 